\title{
INDÍCIOS DE CRIATIVIDADE E INOVAÇÃO NO PROCESSO DE FORMAÇÃO CONTINUADA
}

\author{
Maria José de PINHO $^{1}$ \\ Maria José da Silva MORAIS ${ }^{2}$ \\ Jocyléia Santana dos SANTOS $^{3}$
}

RESUMO: Este artigo objetivou identificar, por meio de documentos e relatos de professores da Secretaria Municipal da Educação de Palmas, os indícios de prática criativa e inovadora no processo de formação continuada dos professores dos anos iniciais do ensino fundamental. Este trabalho caracteriza-se como abordagem qualitativa, com caráter exploratório. Os procedimentos técnicos adotados para a realização deste estudo incluem revisão bibliográfica, análise documental e pesquisa de campo (entrevistas). Para haver mudanças nas práticas metodológicas faz-se imprescindível a percepção docente de que o conhecimento é um contínuo aprender. Portanto, ao investigar as experiências pessoais e educacionais de professores, buscouse evidenciar a memória e a subjetividade desses sujeitos, no sentido de desvelar possibilidades de ações criativas e inovadoras no processo educacional.

PALAVRAS-CHAVE: Memória de professores. Inovação e criatividade nas práticas pedagógicas. Formação continuada. História oral.

\section{Introdução}

O século XXI é marcado por profundas mudanças no contexto educacional. Revela-se uma época de transitoriedade entre dois paradigmas, o dominante e o emergente, em que educadores e cidadãos em geral buscam novos sentidos e novas práticas para seu fazer docente ou não.

Segundo Maturana (2000 apud FURLANETTO, 2011), as aprendizagens são baseadas em na história de vida das pessoas. Nessa perspectiva, Costa (2001, p.77) assim afirma: “[...] ao contar história, o narrador, ao constituir os fatos, reordena seus próprios valores, faz surgir ou fortalece o despertar, a comunicação do eu com os

\footnotetext{
${ }^{1}$ Doutora em Educação e Currículo. PUC - Pontifícia Universidade Católica de São Paulo. Professor Associado. UFT - Universidade Federal do Tocantins. Coordena o Programa de Iniciação Científica (PIBIC) e é Bolsista Produtividade CNPq. Palmas - TO - Brasil. 77402-970 - mjpgon@uft.edu.br.

${ }_{2}$ Aluna do Mestrado em Educação. UFT - Universidade Federal do Tocantins. Membro do Grupo de Pesquisa em Rede Internacional Investigando Escolas Criativas e Inovadoras. Bolsista da Capes /CNPQ. Palmas - TO - Brasil.77402-970 - mel.smassis@ gmail.com.

${ }^{3}$ Doutora em História. UFPE - Universidade Federal de Pernambuco. Professor Adjunto e coordenadora do Programa de Pós-Graduação em Educação. UFT - Universidade Federal do Tocantins. Palmas - TO Brasil.77402-970 - jocyleiasantana@gmail.com.
} 
outros, reconstitui a afetividade como característica do homem, retomando o seu lado humano".

Sob esse prisma, o objetivo desta pesquisa foi identificar, por meio de documentos e relatos de professores da Secretaria Municipal da Educação de Palmas, os indícios de prática criativa e inovadora no processo de formação continuada dos professores dos anos iniciais do ensino fundamental.

A motivação para o desenvolvimento de estudos a respeito desta temática justifica-se pela relevância da prática criativa e inovadora no processo de formação docente e ainda pela inquietação pessoal demonstrada pelos professores do curso de formação continuada dos anos iniciais do ensino fundamental do Município de Palmas ao se disporem a relacionar inovação e criatividade na proposta pedagógica.

Objetivou-se ainda explorar as diversas possibilidades que o campo da história oral oferece tendo em vista que esta se caracteriza metodologicamente como uma abordagem qualitativa de cunho exploratório. As técnicas utilizadas para realização deste estudo incluem primeiramente revisão bibliográfica, posteriormente análise documental e pesquisa de campo (entrevistas). Metodologicamente, a pesquisa está organizada nas seguintes etapas:

Revisão bibliográfica, em que se buscou compreender as concepções de criatividade e inovação no contexto educacional brasileiro, bem como ressaltar a importância da história oral para contextualizar as experiências na trajetória docente. Para tanto, fez-se necessária uma fundamentação teórica cujo intuito constituiu em refletir acerca de "novas" concepções na forma de se pensar a inovação (CUNHA, 2005, 2006). A esse respeito, Torre, Pujol e Silva (2013) ressaltam a importância de a prática pedagógica ser construída com base em registros reflexivos elaborados para a construção do conhecimento mais abertos, plurais e desafiadores. Entre os autores estudados estão ainda Alarcão (2001), Nóvoa (1992), Tardif (2012), Nascimento (2013 apud SUANNO; DITTRICH; MAURA, 2013), Alberti (2005), Halbwachs (2006), Thompson (1992) e Meihy (2011).

A revisão bibliográfica foi realizada ao longo da pesquisa ou de acordo com a necessidade de interpretação dos fenômenos.

Com vistas à complementação do estudo, foram analisados documentos, tais como: projetos de formação de professores e relatório anual com atividades, orientados e desenvolvidos pela diretoria de formação continuada da Secretaria Municipal da Educação de Palmas. Vale reafirmar que o conteúdo em questão aborda a formação 
continuada de professores dos anos iniciais do ensino fundamental. Para tanto, adotouse como parâmetro um conjunto de dados coletados de 2010 até o presente momento.

Além dos documentos municipais citados realizou-se coleta de informações por meio de três entrevistas ${ }^{4}$ semiestruturadas direcionadas a duas professoras e a uma diretora que fazem parte do processo de formação continuada da Secretaria Municipal de Educação de Palmas. Uma das professoras trabalhou na formação continuada na Secretaria Municipal de Palmas, no primeiro semestre do ano de 2013, e atualmente é gestora do CEMEI Príncipes e Princesas da rede. As entrevistadas são assim denominadas: 'A' - diretora, 'B' - professora e 'C' - professora gestora do CEMEI.

Em conformidade com Alberti (2005), as descrições orais coletadas no contexto histórico permitem ao investigador um ingresso no conhecimento ou pistas acerca dos elementos de difícil acesso por meio de alternativas de investigação (como experiências pessoais e conclusões sob o olhar do entrevistado), e também no que concerne ao objeto que se deseja indagar/pesquisar. Desse modo, compreende-se a oralidade como um significativo recurso de difusão de dados em torno das experiências sociais.

Esta pesquisa assumiu as disposições contidas na Resolução do Conselho Nacional de Saúde no 196/96 (BRASIL, 1996), sobretudo no que diz respeito à ética na pesquisa com seres humanos e ainda com o Termo de Consentimento Livre e Esclarecido que contém todas as informações a respeito dos procedimentos adotados durante a condução da pesquisa, o qual foi assinado pelas entrevistadas. Dessa forma, as informações foram organizadas, analisadas e interpretadas de modo global e individual, com vistas a subsidiar a reflexão quanto à abordagem no processo de formação de professores e suas práticas pedagógicas, além de buscar indícios de inovação e criatividade nos anos iniciais do ensino fundamental.

Em conformidade com a literatura consultada, muitos estudos vêm sendo realizados sobre a formação continuada de professores, sobretudo no que se refere às práticas pedagógicas educacionais que os sistemas de ensino desenvolvem para efetivação dessa formação, haja vista que a sociedade contemporânea reivindica constantemente mudanças na prática educativa brasileira. Percebe-se igualmente que a prática educativa inovadora e criativa é pautada nas múltiplas possibilidades dos processos de ensinar e aprender, uma vez que a inovação requer uma ruptura necessária capaz de reconfigurar o conhecimento para além do que está disposto pela modernidade.

${ }^{4}$ As entrevistas foram realizadas em setembro e outubro de 2013, na cidade de Palmas/ Tocantins. 
Ou seja: é indispensável que haja uma mudança na forma de compreender o conhecimento, sobretudo o ambiente e o meio social.

No entanto, para haver mudanças nas práticas metodológicas, e para que estas incorporem a criatividade no processo de ensinar, é imprescindível a percepção docente de que o conhecimento é um contínuo aprender. Nesse sentido, acredita-se que esta pesquisa permitirá que os professores, por meio de uma abordagem transformadora, reflitam a respeito tanto de sua formação, quanto do seu fazer pedagógico, possibilitando-lhes a compreensão do seu papel social e político como educador crítico.

\title{
Concepções de inovação e criatividade no processo de formação continuada
}

A sociedade contemporânea é marcada por grandes mudanças no contexto educacional, as quais implicam revolução do conhecimento, da informação e de novas tecnologias. Tais transformações, por sua vez, envolvem o âmbito econômico, político e social. Nessa direção, Cunha (2006, p.18) afirma que:

\begin{abstract}
Incentivar o processo de inovação é agir contra um modelo político que impõe, não raras vezes, a homogeneização como paradigma [...] as formas de avaliação externa [...] constituíram um fator de retração da inovação [...] pedagogia de visão única [...] que, por sua natureza, excluem formas alternativas de compreensão de conhecimento e de sua produção.
\end{abstract}

A autora ressalta igualmente a importância de se "[...] tratar a inovação como ruptura paradigmática e dar-lhe uma dimensão emancipatória. Nela não há a perspectiva de negação da história, mas sim a tentativa de partir desta para fazer avançar o processo de mudança." (CUNHA, 2006, p.19).

Nessa perspectiva, faz-se necessário compreender se a sala de aula como espaço “[...] de reprodução e também de inovação pode contribuir para construção de teorias pedagógicas alternativas, através das quais as práticas vivenciadas tornam se a inspiração para construção de novos conhecimentos" (FERNANDES; ZANCHE; KONARZEWSKI, 2006, p.101). Sob esse olhar, tem-se que, para compreender as mudanças educacionais, torna-se indispensável refletir as mudanças no contexto pedagógico, ou seja, “[...] entendermos que a inovação requer uma ruptura necessária que permita reconfigurar o conhecimento para além das regularidades propostas pela modernidade. Ela pressupõe, pois, uma ruptura paradigmática e não apenas a inclusão 
de novidades" (FERNANDES; ZANCHE; KONARZEWSKI, 2006, p.105). Para tanto, essa mudança envolve primeiramente a forma de compreender o conhecimento.

À luz desse entendimento, acredita-se que essa mudança requer primeiramente uma compreensão que ultrapasse os limites de ensinar e aprender, tanto na superação do individualismo quanto na responsabilidade de construção social do conhecimento. De tal modo, as autoras assim afirmam:

Compreendemos que a inovação é tarefa de transgressores. Daqueles que estão convencidos de que a ordem habitual e rotineira do ensino deve ser alterada por novas formas de comunicação didáticas, por novas formas de compreender o mundo e exercer a docência. (FERNANDES; ZANCHE; KONARZEWSKI, 2006, p.105).

Na visão de Cunha (2003 apud BROILO; FRAGA; PEDROSO, 2006), é possível que a palavra inovação também estimule alguns professores a fazerem relações diretas com as novas tecnologias. Entretanto, esta percepção é reducionista e requer uma compreensão do processo educativo além do conteúdo. Cunha (2003 apud BROILO; FRAGA; PEDROSO, 2006, p.117) define que as inovações se "[...] materializam pelo reconhecimento de formas alternativas de saberes e experiências acadêmicas que extrapolam perspectivas de papéis, tempo e espaços tradicionais de ensinar”.

Assim sendo, a entrevistada 'A' considera que as atitudes e práticas inovadoras resultam na superação do modo tradicional de ensinar e aprender, o que acontece da seguinte forma:

A forma tradicional ela vem ainda pela cultura que nós temos, mas é como estava falando, se todos estão buscando uma melhor qualificação eles vão deixar e vão trabalhar a inovação por que hoje com o mercado de trabalho exigente que nós temos e com a expectativa de como se é que se diz de inovação em termos de tecnologias até, se o professor ele não inovar ele vai ser um professor criticado ele vai ser um professor que vai está à margem de qualquer superação do educando porque o educando vai dizer 'ei professor o senhor anda pra traz, vamos ver... Hoje qualquer aluno ele tem as maiores facilidades de acesso a tecnologia enquanto os professores ainda resistem, mas eles estão despertado pra esse buscar dessas práticas inovadoras. (Entrevistada 'A').

Depreende-se do exposto que a concepção de Cunha (2003 apud BROILO; FRAGA; PEDROSO, 2006), em relação à inovação, difere da compreensão da 
entrevistada, uma vez que esta relaciona inovar com as novas tecnologias. Sabe-se, porém, que este processo vai além.

Para Contreras (2002 apud BROILO; FRAGA; PEDROSO, 2006, p.119), a autonomia não está “[...] desvinculada da relação com as pessoas com as quais se trabalha, nem é um padrão fixo de atuação, mas, sim, na busca contínua de aprendizado". A inovação associa-se, pois, com a autonomia quando entendida como ruptura paradigmática, na medida em que assume as relações que abandonam a verticalidade autoritária, e compartilha com o novo que não foi iniciado e nem visto antes pelos alunos.

Segundo Cunha (2001, apud BROILO; FRAGA; PEDROSO, 2006, p.121), quando se amplia a “[...] possibilidade de relacionar a teoria com a prática e o professor estimula seus alunos à elaboração de um conhecimento próprio, a aprendizagem passa a ter muito mais significado". Assim, a inovação nessa perspectiva de estudo afasta a possibilidade de receitas pré-organizadas.

Nessa configuração, Torre (2008, p.88) afirma que o “[...] professor criativo desperta o interesse do aluno pelas artes, tornando-o sensível a essa forma de comunicação. Cabe, pois, afirmar que, sucessivas vezes a 'sensibilidade aos problemas' está relacionada ao "fator da criatividade"”. Então, admite-se que o professor criativo busca compreender as dificuldades, bem como suscitar o desejo pelo desconhecido.

Para Alarcão (2001), na sociedade atual são muitos os desafios que se colocam na formação, vez que esta exige uma reflexão pessoal e coletiva, e isto requer um processo de conscientização progressiva, desenvolvimento contínuo e constante persistência na investigação, como fonte de novos conhecimentos.

\section{Análise documental do processo de formação continuada da rede municipal nos anos iniciais do ensino fundamental}

Nessa perspectiva, faz-se necessário analisar o relatório geral, referente ao período 2010 a 2012, dos Núcleos Tecnológicos Municipais (NTMs) no que se refere à capacitação dos professores no uso das Tecnologias de Informação e Comunicação (TIC). O treinamento visou atender à demanda de formação permanente dos servidores da rede municipal de ensino, permitindo a incorporação do uso das tecnologias computador e internet - aos docentes da rede e através do uso desses recursos de 
ferramentas facilitadoras fomentar novas atividades no processo de ensino aprendizagem. (TOCANTINS, 2010, p.1).

Nessa dimensão, o relatório descreve que os NTMs são criados mediante parceria com o Ministério da Educação (MEC), sendo que dessa parceria resultaram programas e cursos, tais como: Proinfo Integrado, Introdução à Educação Digital, Elaboração de Projetos, entre outros. Tais programas têm como objetivo “[...] capacitar os professores e gestores escolares para que eles possam desenvolver projetos integrando as tecnologias de educação existentes na escola". (TOCANTINS, 2010, p.7).

Em se tratando de formação, a “[...] implantação dos NTMs em Palmas veio a somar com as diversas atividades relacionadas à educação voltadas para um ensino de qualidade, firmando-se - gradativamente - como referência nacional". (TOCANTINS, 2010, p.15).

Outro programa assumido por todos os governantes da Federação brasileira (Distrito Federal, Estados e Municípios) foi o Pacto Nacional Pela Alfabetização na Idade Certa (PNAIC). "É um programa integrado cujo objetivo é a alfabetização em Língua Portuguesa e Matemática, até o $3^{\circ}$ ano do Ensino Fundamental, de todas as crianças das escolas municipais e estaduais, urbanas e rurais, do Brasil”. (TOCANTINS, 2013a, p.1).

De acordo com os relatos das professoras entrevistadas 'A' e 'B', o programa traz grandes avanços ao processo de ensino e aprendizagem dos alunos, uma vez que visa também à alfabetização na idade certa, além de fomentar a qualidade do ensino.

Outro projeto que a Diretoria de Formação Continuada desenvolve é o Projeto Trilhas que tem como foco, possibilitar aos professores o acesso ao material didático pedagógico, para que os mesmos pudessem manusear, conhecer e sugerir metodologias de trabalho na sala de aula. Nesse aspecto, o referido projeto é definido como:

[...] um conjunto de materiais elaborados para instrumentalizar e apoiar o trabalho docente no campo da leitura, escrita e oralidade, com crianças de $6^{\circ} \mathrm{s}$ anos, com o objetivo de inseri-las em um universo letrado. Os materiais estão compostos por diferentes materiais, de uso do professor e dos alunos, que visam criar oportunidades para que crianças em processo de alfabetização tenham maior acesso à literatura infantil e, consequentemente à cultura escrita. (TOCANTINS, 2012, p.1).

Sob esse olhar, o Projeto Trilhas tem como principal objetivo "[...] orientar e instrumentalizar os professores e diretores de escolas para o trabalho com os alunos de 
$6^{\circ} \mathrm{s}$ anos, com foco no desenvolvimento de competências e habilidades de leitura e escrita" (TOCANTINS, 2012, p.2). As professoras formadoras possibilitaram o acesso ao material didático pedagógico aos cursistas para que estes pudessem manuseá-lo, conhecê-lo e sugerir metodologias de trabalho em sala de aula.

Cabe destacar ainda o Programa de Alfabetização Pró-Letramento que, por sua vez, é um programa de formação continuada

[...] de professores(as) para melhoria da qualidade de aprendizagem da leitura/escrita, interpretação de Linguagem e Matemática nas anos/séries iniciais do ensino fundamental, promovendo um diálogo reflexivo sobre papéis e responsabilidades de práticas pedagógicas dos envolvidos neste processo educacional, visando à ampliação de saberes nas disciplinas de "Português e Matemática", tidas como áreas críticas do conhecimento humano. (TOCANTINS, 2013b, p.1).

As ações de formação continuada devem criar condições para que os professores desenvolvam conhecimentos que possibilitem a compreensão da matemática e da linguagem e seus respectivos processos de aprendizagem abrangendo as seguintes competências:

[...] a formação de professoras e de eleição de conteúdos, metodologias, organizações curriculares institucionais e avaliação; pautar-se em princípios da ética democrática: dignidade humana, justiça, respeito mútuo, participação, responsabilidade, diálogo e solidariedade, atuando como profissionais e cidadãos, repensando suas práticas em sala de aula, buscando, aos poucos, uma mudança de perspectiva sobre como ensinar e aprender matemática; desenvolver conhecimentos que possibilitem a compreensão da matemática e da linguagem e seus processos de ensino aprendizagem. (TOCANTINS, 2013b, p.1).

O material deste curso está divido em oito fascículos. Cada um deles tem uma estrutura mais ou menos fixa composta de leituras e resolução de atividades presencial e extraclasse. Nos estudos presenciais é oferecida uma metodologia dinâmica com apresentação de seminários, leitura coletiva, individual, músicas, jogos, brincadeiras, vídeos, debates, passeio, dramatização, brincadeiras lúdicas e cantigas de roda (TOCANTINS, 2013b).

Em relação aos programas de formação realizados pela Secretaria Municipal de Educação de Palmas, cabe destacar dois deles: o PACTO e o Pró-Letramento. Apesar de focarem apenas as disciplinas de Português e Matemática, estes têm alguns indícios de inovação e criatividade, pois se observou que os professores formadores desenvolvem 
bons trabalhos para mudança da prática dos professores cursistas da rede. Os cursos propiciam aos referidos professores formação teórica e atividades práticas para desenvolverem atividades diferenciadas com os alunos em sala de aula.

\section{As narrativas e suas múltiplas possibilidades}

Acredita-se que, ao pensar nessas novas formas de ensinar e aprender, seja fundamental o uso das narrativas orais, uma vez que elas permitem ao docente refletir sobre suas experiências e trajetórias pedagógicas. Nesse contexto, afirma Bosi (2004, apud CUNHA, 2006, p.35): "Ele evoca, dá voz, faz falar, diz de novo o conteúdo de suas vivências. Enquanto evoca, ele está vivendo atualmente e com intensidade nova sua experiência".

Nesse contexto, Thompson (1992, p.44) diz que a "[...] história oral é uma história construída em torno de pessoas. Ela lança vida para dentro da própria história e isso alarga seu campo de ação". Assim, a história oral é um método que justifica o enfoque do sujeito, a análise dos relatos, bem como as questões sociais neles presentes. Ao mesmo tempo em que tem a capacidade de recuperar os aspectos individuais de cada sujeito, propicia uma memória coletiva. Nesses termos, pode-se dizer que as narrativas sejam

[...] uma das formas de comunicação do homem com o mundo. Narrar oralmente faz parte da condição humana, é dar existência a àquilo que se narra. Nesse sentido, as narrativas, a despeito de serem fragmentadas, continuam existindo como reinterpretações dos fatos do presente ou do passado, com o simples propósito do entretenimento e de tornar viva a memória do passado [...]. (COSTA, 2001, p.76).

Ante o exposto, infere-se que as narrativas podem apresentar fragmentos na oralidade do sujeito depoente, mas elas não podem ser tratadas apenas como documento, elas podem também transmitir informações. Em conformidade essa discussão, Santos e Araújo (2007, p.197) asseguram que:

A História Oral temática parte de um assunto específico, preestabelecido. A objetividade é mais direta, aproximando-se mais da apresentação de trabalhos analíticos em diferentes áreas do conhecimento acadêmico. Procura buscar a verdade pela narrativa de quem presenciou um acontecimento, ou dele tenha alguma versão. Nesta modalidade, os detalhes da história pessoal do narrador só 
interessam quando se relacionam ou revelam aspectos úteis à informação temática.

Nessa ótica, a história oral temática parte de assunto específico, preestabelecido, e busca a verdade pela narrativa de quem presenciou um acontecimento ou dele tenha alguma versão. Portanto, busca objetividade do entrevistado sobre temas específicos, permitindo a análise de suas experiências e trajetórias (MEIHY, 2011).

Para Meihy (2011, p.46), é fundamental a compreensão de que todo “[...] processo histórico é sempre inacabado, a continuidade que move os grupos junta pessoas com interesses comuns e lhes garante a personalidade social". È básico que se reconheçam os elementos fundamentais que unem e dão sentido às experiências vividas coletivamente, tais como os testemunhos, opiniões e visões de mundo essenciais para compreensão do relacionamento entre o passado e o presente em constante processo de mudança. Tem conhecimento que o trabalho com entrevista ou memória viva de forma oral implica mecanismos para compreensão da dinâmica social, bem como para trabalhar a consciência dos cidadãos, tal como destaca Halbwachs (2006), a seguir.

\begin{abstract}
Assim que evocamos juntos diversas circunstâncias que cada um de nós lembramos (e que não são as mesmas, embora relacionadas ao mesmo evento), conseguimos pensar, recordar em comum; os fatos de passado assumem importância maior e acreditamos revivê-los com maior intensidade, porque não estamos mais a sós ao representá-los para nós. Não os vemos agora como os víamos outrora, quando ao mesmo tempo olhávamos com os nossos olhos e com os olhos de outrem. (HALBWACHS, 2006, p.29).
\end{abstract}

Sob esse olhar, a conservação de lembranças faz com que ao revelá-las, juntamente com estas são liberadas expressões de sensibilidade emocional, ou seja, falar sobre um tema específico faz despertar sentidos singulares importantes.

Sob esses prisma, a entrevistada 'A' relata a forma como a Secretaria Municipal de Educação realiza uma trajetória inovadora na formação continuada dos professores dos anos iniciais, assim definida:

Olha dizer pra você que a gente está evoluindo nessa questão das práticas inovadoras a gente ainda encontra muitos profissionais ainda resistentes aquela prática antiga de como eu fazia é que dava certo que agora vem com inovação que isso não dá certo, mas a gente acredita que está contagiando a todos nesse fazer diferente numa prática que possa de fato tanto satisfazê-lo como profissionalmente como é atingir um objetivo que é o ensino de qualidade. Hoje o Brasil 
ele preconiza uma educação de qualidade para todos e não poderia ficar diferente com os profissionais comprar essa ideia, 'né' se a Secretaria esta possibilitando formas de metodologias diferenciadas pra que ele possa ser um inovador nada mais justo que os profissionais comprar essa ideia e fazer aos poucos a gente está conseguind [...]. (Entrevistada 'A').

Para a entrevistada ' $A$ ' ainda há muitos profissionais resistentes a um fazer que busque uma ação pautada na transformação do sujeito. Embora apenas "comprar a ideia" de acordo com os autores estudados não seja suficiente para inovar no aspecto pedagógico, esta é uma ação que propõe reformar a instituição e as mentes de cada indivíduo para que, de fato, aconteça a transformação desejada.

$\mathrm{Na}$ concepção da entrevistada 'C', esse aspecto não difere ao perguntar se o professor consegue trabalhar de forma transdisciplinar, pois ela assim afirma:

\begin{abstract}
Existe uma dificuldade, eu acredito que muita gente tenha entendido essa proposta, esse transdisciplinar, essa união entre as disciplinas, $e$ o trans que você percebe que existe não são gavetinhas há por que é português e matemática, os assuntos então interligados, os conteúdos estejam interligados, ainda existe uma dificuldade, de trazer atualidades, de trazer temas, de submeter a realidade de você fazer essa conexão, ai eu chamo, eu chamo não, a teoria da aprendizagem significativa sabe, então as vezes eu não tenho trabalhado isso, a aprendizagem ela está sendo significativa, eu estou buscando a prática também, a rotina desse meu aluno, então o que as vezes acontece o professor vai trabalhando à revelia, então fica naquele conteúdo que não tem significado nenhum pra meu aluno, a não ser pra fazer uma prova, pra poder passar de ano, e o que realmente fica desse conteúdo, então eu vejo que gente precisa avançar nesse transdisciplinar, ainda tem muita coisa pra avançar, não estou te dizendo que nós sejamos rasos [...]. (Entrevistada ' $\mathrm{C}$ ').
\end{abstract}

No relato da professora é nítida a compreensão que tem da necessidade de mudança no aspecto do ensino envolvendo a dimensão global de ensinar e aprender, para que de fato ocorra a aprendizagem significativa para o aluno.

Nóvoa (1992) chama a atenção para a necessidade de se trabalhar de forma diversificada nos modelos e nas práticas de formação instituindo novas relações dos professores com o saber pedagógico e científico. Ele assim afirma:

A formação de professores deve ser concebida como uma das componentes de mudança em conexão estreita com os outros setores e áreas de intervenção, e não como uma espécie de condição prévia da mudança. A formação não se faz antes da mudança, faz-se durante, 
produz-se nesse esforço de inovação e de procura dos melhores percursos para a transformação da escola. (NÓVOA, 1992, p.28).

Para tanto, faz-se mister perceber que a mudança educacional tanto depende dos professores, quanto das transformações das práticas pedagógicas em sala de aula. Nesse foco, a entrevistada ' $\mathrm{B}$ ' relata a respeito do envolvimento dos professores quando é aplicada a formação.

Uns eles abraça a causa a proposta, outros ficam alheios infelizmente [...] Infelizmente sempre eles acham que vai dar trabalho 'né', tem um grupo que acha, porque tem as atividades pra fazer, todo módulo a gente estuda ele juntos na formação e a gente aplica as atividades pertinentes, mas eles vão ter que fazer as atividades uma atividade daquelas com os alunos, mas muitos deles não fazem e outros fazem a coisa mais linda como você viu ai a proposta eles desenvolvem na integra, mas tem uns que não aderem e ai você que é uma simples orientadora você não pode forçar, porque tem a gestão, tem o supervisor tem tudo que está lá, que ai eles dão maior importância, $e$ uma das deficiências ainda que eles reclamam muito é a falta de um referencial específico da rede, a educação infantil e a educação do campo tem, agora o ensino fundamental, é pra ser construído agora. (Entrevistada 'B').

Com esse pensamento, Cardoso (1997 apud CUNHA, 2006, p.51) remete à seguinte acepção:

[...] a inovação pedagógica traz algo de 'novo', ou seja, algo ainda não estreado; é uma mudança, mas intencional e bem evidente; exige um esforço deliberado e conscientemente assumido; requer uma ação persistente; tenciona melhorar a prática educativa; o seu processo deve ser avaliado; e para se poder constituir e desenvolver, requer componentes integrados de pensamento de ação. (CUNHA, 2006, p.51).

Percebe-se, pelo exposto, que a inovação não é uma mudança qualquer, necessita de uma ruptura com a situação vigente, esta é uma ação deliberada e conscientemente assumida, ou seja, é algo que muda o instruído no seu essencial.

A entrevistada ' $\mathrm{C}$ ' entende a inovação nas práticas pedagógicas em sala de aula da seguinte forma:

Eu vejo primeiro é investimento, boa vontade, importantíssimo a boa vontade do profissional esse desejo de querer, de aprender, de crescer, então assim eu vejo mais é isso, investimento, essa abertura por parte dos gestores de entender o processo de formação também 
acho importantíssimo, ver que isso trás uma mudança na prática educacional que também é processo, educação é processo não acontece de um dia pra outro, a educação essa excelência é construção, só que pra ser construção tem que ser degrau por degrau, mas tem que ter seguimento. (Entrevistada ' $\mathrm{C}$ ').

Acredita-se que, pensar a inovação requer uma ruptura paradigmática que se refere à interdisciplinaridade como uma alternativa de inovação educativa. Para as autoras citadas a seguir:

A concepção de interdisciplinaridade é mais do que simples atravessamento das fronteiras que estabelecem os territórios de cada disciplina. Ao mesmo tempo em que transpõe tais limites, a interdisciplinaridade se coloca como um elo 'inter' disciplinas e 'inter' práticas do trabalho docente e discente. (BROILO; FRAGA; PEDROSO, 2006, p.124).

Partindo-se desse ponto de vista e da ideia da não-fragmentação do conhecimento, fazem-se necessárias rupturas paradigmáticas e, sobretudo, pensar nas possibilidades de rupturas e construção do novo na perspectiva do ensinar e aprender.

Ante tal pressuposto, a entrevistada 'C' relata ser imprescindível que o professor esteja atento à formação continuada para que ocorra a transformação em seu fazer pedagógico. Nesse viés assim afirma:

Eu acredito que vá além de uma mera contribuição, ela é fundamental para que se tenha mudança de postura diante da instituição, se o professor não tiver essa formação, se a gente não oportunizar esses momentos de reflexão, momentos onde se busque esse conhecimento, provavelmente a coisa não tem o resultado que a gente espera, então hoje mesmo estou aqui conversando com você, e estou participando de uma formação, não é porque eu sou formadora que eu paro, quer dizer eu vou atrás também, agora nós estamos ai com MBIEI com uma missão internacional, vamos até a Coreia do Sul pra que, pra aprender com aquele país, o que eles fizeram pra reverter a situação do país que sempre ficava com os índice lá embaixo e hoje tem os melhores índices [...] A gente está indo pra lá, pra conhecer, veja bem o quanto a formação ela é importante, quer dizer a gente precisa desse aparato, a gente precisa buscar, tomar as forças, além da formação inicial que você tem, o professor não pode parar nunca, o mundo está em constante transformação, alias profissional nenhum pode, sobretudo quem tá atuando junto aos seres humanos, junto de alunos, ai é que não pode parar mesmo, tem que buscar transformação. (Entrevistada, 'C'). 
Para Nascimento (2013, p.90), “[...] a criatividade é exercício da liberdade de pensar, de agir, de ser, além dos padrões que adotamos. Ser criativo implica uma atitude livre, a partir da qual se assume um papel de responsabilidade pela criação (criar + ação) de sua própria realidade".

As considerações da entrevistada 'A' em relação às mudanças ocorridas no processo educacional, principalmente em relação à necessidade de os profissionais criarem e inovarem rumo a uma prática transdisciplinar, são assim expressas:

Então hoje a gente sabe que o saber ele não estático por isso ele perpassa por todas as áreas [...] Então hoje a gente sabe que o ser humano precisa ser trabalhado no todo pra ele ser trabalhado no todo é preciso que a interdisciplinaridade esteja preconizada no desenvolver dos saberes, 'né'; então veja, ele tem que perpassar por todas as áreas do conhecimento para que de fato o aluno seja formado globalmente não existe mais as caixinhas de português de matemática hoje o ensino é interdisciplinar porque requer esse desejo do aluno está completo no seu conhecimento e nos saberes porque a prática dele na hora que ele vai fazer, colocar de fato na prática ele não precisa saber o português da sua caixinha a matemática da sua caixinha não, ele precisa do conhecimento global, então isso implica que o professor esteja cada dia mais inovando e que aluno esteja se apropriando daquilo que o mercado de trabalho tá exigindo. E as avaliações externas, as avaliações externas ela testa o conhecimento do aluno no seu todo então isso precisa ser trabalhado em sala de aula. (Entrevistada 'A').

Infere-se pelo relato da entrevistada que há uma concepção em relação ao trabalho interdisciplinar. Ela sinaliza bem esse conceito e enfatiza que as formas de avaliações atualmente também revelam esse objetivo.

Cabe, porém, salientar que o fazer coletivo é imprescindível na perspectiva da inovação e da criatividade, uma vez que requer um trabalho voltado para as necessidades da escola. Acerca dessa questão, Rajadell (2012) alerta para o fato de que o trabalho coletivo necessita do respeito às diversidades de opiniões, conhecimentos e experiências. Assim, ele define:

Toda mudança requer um reconhecimento do passado, porém sem se deter nele; mudar significa refletir sobre o que já temos e avançar um passo adiante. Porém, toda mudança positiva radica no trabalho compartilhado, cada pessoa oferecendo suas contribuições, a sua experiência e suas reflexões a este respeito. $\mathrm{O}$ ensino em equipe requer trabalho em equipe um coletivo que possua um ar de neutralidade, tolerância e respeito a determinados temas, atividades e 
abertura a sugestões e críticas dos demais, embora sempre sob o ambiente positivo. (RAJADELL, 2012, p.130).

Nesse entendimento, Tardif (2012) atesta que o saber é social, pois é partilhado por todo um grupo de agentes os professores que possuem formação comum (apesar de uns ter mais ou menos variável conforme os níveis e graus de ensino) estes sujeitos trabalham numa mesma instituição. Destarte, o autor define que,

[...] por causa da estrutura coletiva de seu trabalho cotidiano, a condicionamento e recursos comparáveis, entre os quais programas, materiais a serem ensinadas, regras de estabelecimento, etc. Desse ponto de vista, as representações ou práticas de um professor especifico, por mais originais que sejam, ganham sentido somente quando colocadas em destaque em relação a essa situação coletiva de trabalho. (TARDIF, 2012, p.12).

Em conformidade com o entendimento da entrevistada 'B', havia planejamento coletivo na formação continuada. A esse respeito, ela assim se expressa: "ele acontecia todo mês, na última sexta feita do mês a gente tirava o período da tarde pra ter a socialização dos cursos. Aqui ano passado, esse ano ainda, é porque assim mudou a gestão". Infere-se que o trabalho coletivo é fundamental para a mudança de forma global dos sujeitos envolvidos em uma instituição. Para tanto, é notório que não são ações isoladas ou esporádicas.

Com respaldo nos autores estudados, nos documentos e relatos, deduz-se que são imprescindíveis práticas pedagógicas pautadas na dimensão global do sujeito. Essa ação requer disposição do educador no processo de ensino e aprendizagem que ultrapasse a forma linear e fragmentada de ensinar e aprender.

\section{Considerações finais}

À luz da literatura consultada, deu-se ênfase, neste estudo, à análise dos relatos dos entrevistados, considerados fundamentais para se compreender que a historia oral não é homogênea, de acordo em que lidamos com situações novas, as quais exigem reflexão apurada para se evitarem interpretações precipitadas.

Buscou-se refletir acerca das mudanças educacionais ocorridas nas práticas pedagógicas e, sobretudo, compreender a importância da inovação educacional e das 
metodologias que incorporam a criatividade no processo de ensinar, sendo fundamental a percepção docente de que o conhecimento é um contínuo aprender.

Além disso, é importante que os sujeitos desse processo sejam competentes em suas áreas de conhecimento, ou seja, que saibam perceber e construir relações com outros saberes. Para tanto, apoiando-se entrevistas realizadas e na análise dos relatos da diretora e professoras, pode-se afirmar que a Secretaria da Educação de Palmas por meio da Diretoria de Formação Continuada tem buscado mudanças na prática pedagógica dos professores da rede por meio de constantes cursos e principalmente ações em sala de aula.

Cabe, porém, ressaltar que esse trabalho necessita ir além de ações individuais, ou seja, que as atividades sejam realizadas pelos professores de formação continuada de forma coletiva e se caracterizem pelos indícios de prática criativa e inovadora. Para tanto, faz-se urgente agregar conhecimentos que vão além das disciplinas e que, de fato, tenha um saber global, envolvendo todos os sujeitos do processo e de forma contínua.

Ante o que foi discutido, entende-se a necessidade do rompimento com o modelo dominante que trabalha o ensino de forma disciplinar com foco nos conteúdos e sem articulação com outros saberes. É notório que esse processo de ensinoaprendizagem é desarticulado e principalmente sem envolvimento e significação para o educando.

Nesta pesquisa buscou-se identificar os indícios de criatividade e inovação por meio dos relatos de professores e diretora do processo de formação continuada dos anos iniciais do ensino fundamental da Secretaria Municipal de Palmas. Face ao exposto, é possível compreender a importância da memória ou dos relatos, condição essencial para a contribuição dos processos atrelados ao fazer desses sujeitos.

$\mathrm{Na}$ análise documental, ficou visível que a inovação ainda está relacionada às novas tecnologias, não que este fator não seja importante para mudanças nas práticas pedagógicas, mas é fundamental que essa concepção vá além desse aspecto.

Infere-se ademais que, nas últimas décadas, as transformações empreendidas no mundo requerem novas exigências e desafios para o trabalho pedagógico realizado pelos sistemas escolares. De modo especial, a área de formação de professores aponta para um balanço do ensino como prática social. Nessa direção, estudos e pesquisas vêm apontando, ainda que de forma tímida, para as transformações no aspecto da inovação e criatividade provocadas na prática docente. 
Convém aqui reconhecer que as mudanças relatadas pelas professoras de formação continuada dos anos iniciais do ensino fundamental da rede Municipal de Educação ainda precisam avançar em muitos aspectos. Para objetivar uma prática transdisciplinar são necessárias modificações nos aspectos físicos, materiais e, sobretudo, mudança de postura, além de constante formação do profissional. Logo, é imprescindível que no trabalho docente se tenha consciência das situações de mudanças que ocorrem na sociedade e que esta compreensão leve a práticas inovadoras no processo educacional. Enfim, que o ensinar e aprender revelem significados na condição profissional.

\title{
EVIDENCE OF INNOVATION AND CREATIVITY OF THE CONTINUING EDUCATION PROCESS
}

\begin{abstract}
This paper purposes to identify by means of documents and teacher report of the Secretaria Municipal de Palmas, evidence of creative and innovative practice in the process of continuing education of teachers in the early years of elementary school. This work is an exploratory qualitative approach. The technical procedures adopted to achieve this result were: literature review, document analysis and field research (interviews). It's necessary changes in methodological practices to develop in teacher perception, that knowledge is a continual learning. Therefore, to investigate the personal and educational experiences of teachers, sought to highlight the memory and subjectivity of these subjects, seeking opportunities for creative and innovative actions in the educational process.
\end{abstract}

KEYWORDS: Memory of teacher. Innovation and creativity in teaching practices. Continuing education. Oral history.

\section{REFERÊNCIAS}

ALARCÃO, I. Escola reflexiva e nova racionalidade. Porto Alegre: ARTMED, 2001. $261 \mathrm{p}$.

ALBERTI, V. Manual de história oral. 3.ed. Rio de Janeiro: Ed. da FGV, 2005.

BRASIL. Ministério da Saúde. Conselho Nacional de Saúde. Resolução no 196, de 10 de outubro de 1996. Brasília: Ministério da Saúde, 1996.

BROILO, C. L.; FRAGA, E. T.; PEDROSO, M. B. Os alunos como parceiros: adesões e resistências as inovações no espaço de sala de aula. In: CUNHA, M. I. (Org.).

Pedagogia universitária: energias emancipatórias em tempos neoliberais. Araraquara: Junqueira \& Marins, 2006. p.109 -133. 
COSTA, C. B. Memórias compartilhadas: os contos de história. In: COSTA, C. B.; MAGALHÃES, N. A. (Org). Contar história, fazer história: historia cultura e memória. Brasília: Paralelo 15, 2001. p.73-84.

CUNHA, M. I. A universidade: desafios políticos e epistemológicos. In: (Org.).

Pedagogia universitária: energias emancipatórias em tempos neoliberais. Araraquara: Junqueira \& Marins, 2006. p.13-29.

O professor universitário na transição de paradigmas. 2.ed. Araraquara: Junqueira \& Marins, 2005.

FERNANDES, C. M. B.; ZANCHE, M. B.; KONARZEWSKI, S. E. Pedagogia universitária: refletindo sobre os impasses e desafios para a experiência inovadora. In: CUNHA, M. I. (Org.). Pedagogia universitária: energias emancipatórias em tempos neoliberais. Araraquara: Junqueira \& Marins, 2006. p.97- 125.

FURLANETTO, E. C. Formação e transdisciplinaridade: o encontro com a experiência. In: .; TORRE, S.; ZWIEREWICZ, M. Formação docente e pesquisa

interdisciplinar : criar e inovar com outra consciência. Blumenau: Nova Letra, 2011. p.125-157.

HALBWACHS, M. A memória coletiva. São Paulo: Centauro, 2006.

MEIHY, J. C. B. Guia prático de história oral: para empresas e universidades, comunidades, famílias. São Paulo: Contexto, 2011.

NASCIMENTO, P. L. Parâmetros para análise-síntese de práticas educativas. In: SUANNO, M. V. R.; DITTRICH, M. G.; MAURA, A. M. P. (Org.). Resiliência, criatividade e inovação. Goiânia: UEG / Editora América, 2013. p.75-98.

NÓVOA, A. Formação de professores e profissão docente. Lisboa: Publicações Dom Quixote, 1992.

RAJADELL, N. A importância das estratégias didáticas em toda ação formativa. In: SUANNO, M. V. R.; PUIGGRÓS, N. R. (Org.). Didática e formação dos professores: perspectivas e inovações. Goiânia: CEPED Publicações / PUC Goiás, 2012. p.105-132.

SANTOS, S. M.; ARAÚJO, O. R. História oral: vozes, narrativas e textos. Cadernos de História da Educação, Uberlândia, n.6, jan./dez. 2007. Disponível em: <http://www.seer.ufu.br/index.php/che/article/view/282/289>. Acesso em: 20 ago. 2013.

TARDIF, M. Saberes docentes e formação profissional. 13.ed. Petrópolis: Vozes, 2012.

TOCANTINS (Estado). Secretaria Municipal de Educação. Núcleos Tecnológicos Municipais - NTMs. Gerência de Formação Permanente 2010, 2011 e 2012. Palmas: Secretaria Municipal de Educação, 2010. 
Secretaria Municipal de Educação. Programa de Alfabetização Pró-

letramento. Palmas: Secretaria Municipal de Educação, 2013b.

Secretaria Municipal de Educação. Projeto Trilhas. Palmas: Secretaria Municipal de Educação, 2012.

TORRE, S. Professor e alunos criativos. In:

Criatividade aplicada: recursos para uma formação criativa. São Paulo: Madras, 2008. p.81-103.

; PUJOL, A. M.; SILVA, V. L. S. (Org.). Inovando na sala de aula instituições transformadoras. Blumenau: Nova Letra, 2013.

THOMPSON, P. A voz do passado: história oral. 3.ed. Rio de Janeiro: Paz e Terra, 1992. 